Fabio Henrique Dias Maximo, Luísa Monteiro de Oliveira, Rodrigo Octávio

Urban Bernardes de Menezes, Edson José Carpintero Rezende *

\title{
0 Design como Promotor do Conforto da Sociedade de Consumo
}

Fabio Henrique Dias Maximo é professor adjunto do Departamento de Design e Expressão Gráfica (DEG) da Universidade Federal do Amazonas (UFAM). Doutorando do Programa de Pós-Graduação em Design na Escola de Design (ED) da Universidade do Estado de Minas Gerais (UEMG). Pesquisador bolsista de pós-graduação da Fundação de Amparo à Pesquisa do Estado do Amazonas (FAPEAM) edital n. 001/2019 - PROPG-CAPES/FAPEAM. Graduação em Desenho Industrial pela UFAM (2008). Especialização em Planejamento de Transportes pela UFAM (2009). Mestrado em Ciências Florestais e Ambientais pela UFAM (2013). Experiência na área de Desenho Industrial, com ênfase em Desenho de Produto. $<$ fabiomaximo@ufam.edu.br> ORCID: 0000-0002-3614-7165
Resumo Por vezes o design produz mercadorias que satisfazem os desejos do indivíduo apenas pelo consumo. O sistema socioeconômico vigente está alicerçado sobre o pressuposto de que a produção em massa pode proporcionar aos indivíduos o incremento da sua qualidade de vida por meio do consumo de produtos e serviços. Nesse panorama, discutiremos a configuração da sociedade de consumo e as contribuições do design para o bem-estar. A discussão se fará em duas frentes: demonstrar como o sentido de bem-estar e de conforto foi modificado pelo comércio de produtos e serviços e apontar como o planejamento de projetos de design contribui para manutenção desse sistema socioeconômico baseado no consumo. A discussão neste artigo busca demonstrar que o crescimento econômico, o desenvolvimento industrial e o aumento da produção que viabiliza novos produtos e que facilita o acesso dessas mercadorias a toda a sociedade não proporciona o tão almejado bem-estar social de uma população.

Palavras chave Design, Consumo, Ética, Bem-estar. 


\title{
Design as a Promoter of Consumer Society Comfort
}

Luísa Monteiro de Oliveira é discente no programa de pós-graduação da Universidade do Estado de Minas Gerais (UEMG), Mestrado em Design, Sustentabilidade e Inovação, formada em Design de Produto pela UEMG (2017). Como profissional, atua com Design cerâmico, valorização de culturas artesanais produtivas por meio do design e com promoção da inovação.

<luisamont.oliveira@gmail.com > ORCID: 0000-0002-8742-015X

\begin{abstract}
Sometimes design produces goods that satisfy the individual's desires just by consumption. The current socioeconomic system is based on the assumption that mass production can provide individuals with an increase in their quality of life through the consumption of products and services. In this panorama, we will discuss the configuration of the consumer society and the contributions of design to well-being. The discussion will take place on two fronts: to demonstrate how the sense of well-being and comfort were modified by the trade in products and services and; to point out how the planning of design projects contributes to the maintenance of this socioeconomic system based on consumption. The discussion in this article seeks to demonstrate that economic growth, industrial development and increased production that makes new products feasible and that facilitates the access of these goods to the whole society does not provide the much desired social well-being of a population.
\end{abstract}

Keywords Design, Consumption, Ethic, Well-being.

\section{El diseño como promotor del confort de la sociedad de consumo}

Rodrigo Octávio Urban Bernardes de Menezes possui especialização em $\mathrm{Ad}$ vocacia de Família e Sucessões pela Universidade FUMEC (2018), especialização em Psicopedagogia Institucional pela Universidade Norte do Paraná (2020), graduação em Direito pela Pontifícia Universidade Católica de Minas Gerais (2002), graduação em Psicologia pela Universidade FUMEC (2002) e graduação em Design Gráfico pela Universidade do Estado de Minas Gerais (2019). Membro da Comissão de Gestão, Empreendedorismo e Inovação da Ordem dos Advogados do Brasil/MG. Atualmente é advogado MBL Advogados Associados.

<roubmenezes@gmail.com> ORCID: 0000-0003-4627-0914
Resumen A veces, el diseño produce bienes que satisfacen los deseos del individuo simplemente mediante el consumo. El sistema socioeconómico actual se basa en el supuesto de que la producción en masa puede proporcionar a las personas un aumento de su calidad de vida a través del consumo de productos y servicios. En este panorama, discutiremos la configuración de la sociedad de consumo y las contribuciones del diseño al bienestar. La discusión se desarrollará en dos frentes: demostrar cómo la sensación de bienestar y comodidad ha sido modificada por la venta de productos y servicios y señalar cómo la planificación de proyectos de diseño contribuye al mantenimiento de este sistema socioeconómico basado en el consumo. La discusión en este artículo busca demostrar que el crecimiento económico, el desarrollo industrial y el aumento de la producción que hacen factibles nuevos productos y que facilitan el acceso de estos bienes al conjunto de la sociedad no brindan el tan deseado bienestar social de una población.

Palabras clave Diseño, Consumo, Ética, Bienestar. 


\section{Introdução}

Edson José Carpintero Rezende possui graduação em Odontologia, licenciatura em Ciências, pós-graduação "Latu sensu" em Microbiologia, pós-graduação "Latu sensu" em Odontologia Legal, mestrado em Saúde Coletiva, doutorado em Ciências da Saúde e Pós-doutorado em Estudos Interdisciplinares do Lazer. Atualmente é professor efetivo e pesquisador nos cursos de graduação e pós-graduação Latu Sensu e Stricto Sensu na Escola de Design da Universidade do Estado de Minas Gerais. É líder do grupo de pesquisa "Design em interface com a saúde" e professor pesquisador do grupo extensionista e de pesquisa em Design Social, ambos cadastrados no CNPq. <edson.carpintero@uemg.br> ORCID: 0000-0003-0692-0708
O modelo de desenvolvimento econômico, assim como o design, surgiu em meio a um contexto de expansão industrial e de consumo num período pós-guerra, alavancado pelo alto crescimento populacional e de potências capitalistas. Somente agora se compreende como esse sistema, de fato, não resolveu os problemas como a fome, pobreza, educação, e que, por conseguinte, ainda aumentou a desigualdade social. Muito embora, desde a Primeira Revolução Industrial1, todo o planeta tenha enriquecido e se desenvolvido tecnologicamente, chega-se à quarta revolução industrial com os mesmos sintomas. Nesse quadro, caminha-se perigosamente para uma maior concentração das benesses a um grupo seleto de países e empresas que, sobretudo, ditam a direção do desenvolvimento e manutenção do sistema socioeconômico por meio do controle da produção, distribuição, focado no consumo (MORAES; KRUCKEN, 2009; SCHWAB; DAVIS, 2018).

No início, o design, quando da sua implementação efetiva, aparece como uma solução funcional aos problemas do mundo irrequieto e inconstante daquele período industrial em crescimento. Mostrou-se como uma nova ferramenta a serviço do homem para que resolvesse, de forma prática e útil, os novos problemas que surgiram em decorrência das transformações econômicas, sociais e culturais da época. Para Cardoso (2012), é a partir da Primeira Revolução Industrial que o design deixa de ser uma característica que existe naturalmente nos produtos para se tornar objeto de investigação e fomento, visando servir à ideologia da época, relacionada à funcionalidade e objetivando o consumo em massa. Segundo Cardoso (2012, p. 15), "nunca na história da humanidade, tantas pessoas haviam tido a oportunidade de comprar tantas coisas". Naquele período, a indústria consolidou o uso de máquinas, no intuito de produzir em larga escala e relegando para segundo plano a manufatura e o artesanato. Era a criação da sociedade de consumo.

\footnotetext{
As máquinas pré-industriais foram fabricadas empiricamente, ao passo que as industriais o são tecnicamente. [...] Daí que, a partir da Revolução Industrial, o boi deu lugar à locomotiva, e o cavalo, ao avião. O boi e o cavalo eram impossíveis de serem feitos tecnicamente (FLUSSER; CARDOSO, 2017, p. 44).
}

A produção em massa resultou no declínio da qualidade e da beleza dos produtos, que passaram a ser fabricados com o propósito precípuo de atender à quantidade de demanda dos consumidores emergentes, intencionando exclusivamente a comercialização e o lucro. Não obstante, diante desse novo estilo de vida, e da produção em massa, encontraram colocação social os artistas, arquitetos, reformadores, burocratas e outros formadores de opinião com a intenção de determinar as características dominantes das mercadorias ofertadas, para que formassem o gosto da população, com re- 
flexos no aumento do consumo e do lucro dos fabricantes. A produção visava ao consumo cada vez maior de produtos selecionados pelos fabricantes, e os agentes sociais abarcaram essa ideologia.

Entre 1850 e 1930, aproximadamente, três gerações de novos profissionais - alguns já apelidados de "designers" - dedicaram seus esforços à imensa tarefa de conformar a estrutura e aparência dos artefatos de modo que ficassem mais atraentes e eficientes (CARDOSO, 2012, p. 16).

Para Pinto (1997), é a partir da consolidação dos ideais igualitários das revoluções burguesas que os valores da igualdade e felicidade (entendidos como bem-estar) vão se aproximando e se popularizando. Assim, torna-se necessária a tangibilidade dessa sensação, que é traduzida pelo consumo e aquisição de bens. Portanto, esse modelo só pode se efetivar diante da multiplicação da oferta dos produtos e da ilusão de abundância e de acesso igualitário à produção. Insta ressaltar que a produção é ditada não somente pelas necessidades do consumo e da população, mas também pela imposição velada criada pelos produtores e setores econômicos, sob um discurso de universalização do acesso aos bens.

Baudrillard procura demonstrar que o consumo é um fenômeno social, mais que econômico, articulado pela lógica de um desejo forjado a partir de "necessidades" criadas pelos setores produtivos e assentado numa lógica de igualdade social, de uma democracia em termos do valor de uso dos objetos, implícito em sua oferta (PINTO, 1997, p. 19-20).

Não obstante, procura-se fornecer mais e mais opções para o consumidor, facilitando o acesso aos bens, mas, de forma intrínseca, cria-se uma diferenciação social fundada na exibição de tais bens, e na diferenciação do valor simbólico que eles carregam. Nas palavras de Pinto (1997, p. 20): "Paradoxalmente, entretanto, o desejo se funda no princípio da diferença e, no caso do consumo, a diferença se instaura no valor de signo do objeto". 


\section{Consumo para bem-estar}

O sistema socioeconômico configurado até então é regulado pela promessa de proporcionar um bem-estar coletivo maior por meio do consumo de bens e serviços. Nesse sistema, o incremento da produção é vital, por isso é necessário engajar o máximo de tempo dos cidadãos em prol do trabalho (MORAES; KRUCKEN, 2009). Contudo, como ressalta Bauman (2008), na reflexão trazida em seu livro Vida para consumo, tudo funciona a partir da lógica mercantilista, ou seja, as relações são sempre de compra e venda, seja para produtos, serviços, seja para pessoas, dividindo a sociedade entre produtores e consumidores, tendo os produtores um papel determinante na condução da economia das nações.

Até então, o paradigma estabelecido para o bem-estar coletivo apresentava-se diretamente proporcional à viabilização do consumo amplo de coisas materiais, ou seja, pautado pelo crescimento econômico das nações, tendo os governos o papel de estimular o mercado a aumentar a produção e o consumo na sociedade.

[...] A ideologia do bem-estar consumista não foi construída em resposta às rejeições à modernidade desumanizante do capitalismo, mas pelo desenvolvimento de um modelo individualista, materialista e mercantil do ideal democrático da felicidade (LIPOVETSKY; SERROY, 2014, p. 1918).

As nações, por muito tempo, não se preocuparam, diante da vasta riqueza de recursos naturais, em planejar o destino de todo o resíduo gerado por esse sistema de consumo. Depois de anos, compreende-se como esse ciclo de produção/consumo/bem-estar (Figura 1) é prejudicial, não produzindo uma relação mais amistosa e positiva com o meio-ambiente, uma vez que extrai o máximo de recursos e o polui.

Consoante Pinto (1997), o discurso do consumo é fundado no princípio do máximo aproveitamento da vida. Sob a lógica da mercantilização dos indivíduos, aqueles que têm possibilidade de consumir produtos e frequentar lugares caros - comumente conhecidos hoje em dia como "instagramáveis" 2 - se tornam pessoas de maior valor e visibilidade, ou, na visão do autor, mercadorias de maior valor. Destarte, o consumo de bens e serviços cria uma forma de relação com o objeto que extrapola o valor da sua necessidade, passa a se relacionar diretamente com a realização pessoal do indivíduo e dita sua posição frente a um grupo social. Assim, o ato de consumir um bem ou um serviço aponta para a diferenciação e distinção social.

Esse comportamento também está diretamente atrelado à cultura da distração e do lazer. Por conseguinte, surge a visão de que as pessoas devem ser propagadoras de si em diversos aspectos da vida, tanto no profissional quanto no afetivo. Isso contribui com a construção de falsas realidades, virtualizadas, o que é possível no mundo virtual e das redes sociais. $O$ consumo se torna uma linguagem, e o produto, um símbolo que, enquanto 


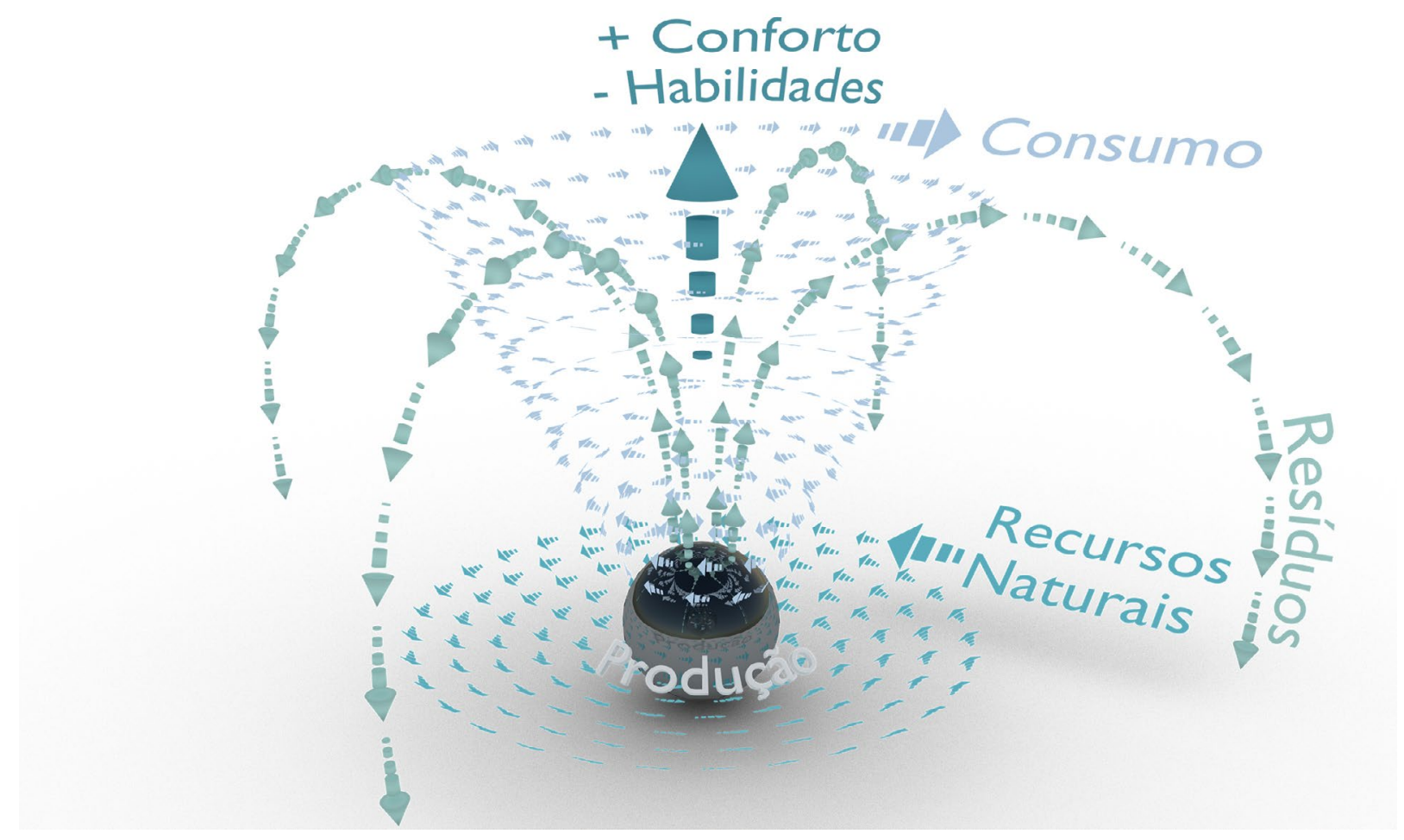

Fig 1. Sistema que ilustra a ideia de

bem-estar pelo consumo

Fonte: Elaborada pelos autores, 2020 é exibido por um indivíduo, ressalta a sua ausência nos outros. Então o suposto bem-estar proporcionado pela possibilidade ampla do consumo funciona de maneira revés, posto que amplia a distância entre as diversas formas de aquisição e apresentação de um mesmo produto. E, vivendo em uma sociedade comparativa, aqueles que não atingem um limite imposto de consumo se sentem excluídos de um grupo social considerado mais elevado, resultando em frustração e mal-estar individual (ARRUDA, 2017; MANZINI, 2008).

Em outra frente, não só o consumo de produtos é posto como um grande referencial para a sensação do bem-estar, mas também há uma supervalorização do entretenimento, ou seja, não há espaço para o tempo contemplativo na pós-modernidade (MANZINI, 2008).

O capitalismo transestético inventou esse tipo de arte, inédito na história, que integra em sua ordem os seguintes princípios: a lógica econômica, o mercado de massa, o marketing, a série, o múltiplo, a obsolescência acelerada, a renovação permanente. Uma arte de massa cujo objetivo não é criar a experiência elitista do Absoluto, da veneração ou do recolhimento, mas lucrar, estimular o consumo de todos através dos prazeres passageiros e imediatos, fáceis, incessantemente renovados e que não exigem nenhum aprendizado, nenhuma competência, nenhum enraizamento ou impregnação culturais particulares (LIPOVETSKY; SERROY, 2014, p. 1082). 
Para Llosa (2013), ocorre uma banalização lúdica da cultura, na qual o valor supremo é divertir-se imediatamente, acima de qualquer outra forma de conhecimento construtivo. $O$ entretenimento tem uma característica fugaz e imediatista, sem qualquer preocupação com o desenvolvimento de um pensamento crítico ou elaborado. Segundo Llosa (2013, p. 70), as pessoas consomem cultura "Só para distrair-se, esquecer-se das coisas sérias, profundas, inquietantes e difíceis, e entregar-se a um devaneio ligeiro, ameno, superficial, alegre e sinceramente estúpido".

Em meio ao mercado de produção de massa, a falta ou escassez de qualquer recurso-natural poderia demonstrar a insustentabilidade desse sistema; no entanto, prontamente a criativamente humana remediou essa deficiência por meio do consumo do entretenimento. $O$ entretenimento como bem imaterial também se torna consumível, porém o tempo contemplativo, o ócio criativo, se tornam recursos escassos e finitos. Como resultado desse processo cada vez mais agressivo e nocivo de consumo, a sociedade começa a se desestabilizar justamente por ignorar ou não perceber mais o meio ambiente, provedor da matéria-prima de seu sistema socioeconômico. Essa relação entre produção e consumo desenfreado e despreocupação com o meio ambiente chegaram a patamares globais, tornando as crises econômicas cada vez mais frequentes e profundas (FLUSSER; CARDOSO, 2017; JAMESON, 2010; MANZINI, 2008).

[...] Desse ponto de vista, a vida consumista merece inúmeras críticas, e não em nome de uma ética ascética revisitada, mas, ao contrário, em nome de um ideal estético superior que se pretenda a serviço da riqueza da existência individual, um ideal que privilegie a sensação de si e do mundo, o recentramento no tempo interior e na emoção do momento, a disponibilidade para o inesperado e o instante vivenciado, a fruição das belezas ao alcance da mão, o luxo da lentidão e da contemplação (LIPOVETSKY; SERROY, 2014, p. 516).

A construção de valor social, sob a lógica do consumismo, acontece a partir do que se tem acesso. Tendo isso em vista, o mercado do entretenimento se estabelece como ponto de escape da realidade, onde tudo está ao alcance dos olhos e, por vezes, das mãos. Nesse cenário, a publicidade se utiliza de arquétipos, como famosos e pessoas influentes, para estimular o consumo com efeito de construir o pertencimento a um determinado estilo de vida almejado (BAUMAN, 2008). 


\begin{abstract}
Numa sociedade sinóptica de viciados em comprar/assistir, os pobres não podem desviar os olhos; não há mais para onde olhar. Quanto maior a liberdade na tela e quanto mais sedutoras as tentações que emanam das vitrines, e mais profundo o sentido da realidade empobrecida, tanto mais irresistível se torna o desejo de experimentar, ainda que por um momento fugaz, o êxtase da escolha (BAUMAN, 2001, p. 104).
\end{abstract}

É indiscutível que a realidade aponta para uma nova mentalidade por meio do surgimento de outros valores para a vida cotidiana. No entanto, por volta da década de 1980, por meio do consumo, surge um novo nicho de mercado: o de produtos ditos ecológicos ou verdes, criando uma oportunidade de trabalho promissora para atuação do design.

[...] é nessa conjuntura complexa, de avanços e retrocessos, que o design se torna fundamental na construção de um processo de inovação social, cultural e tecnológica em harmonia com as demandas ambientais (CAVALCANTI; ARRUDA; NONATO, 2017, p. 45).

A organização das estruturas sociais passa por mudanças com o crescimento da consciência ambiental (ambientalismo), quando surge o termo "sustentabilidade" como princípio do desenvolvimento projetual. Esse pensamento ambientalista começa a avançar e levantar questões a respeito do desperdício, advindo do excesso do consumo que pauta o desenvolvimento socioeconômico das nações até o momento (MANZINI, 2008).

Essas duas dimensões, a exploração excessiva dos recursos naturais e a desigualdade inter e intrageracional na distribuição dos benefícios oriundos dessa exploração, conduziram à reflexão sobre a insustentabilidade ambiental e social dos atuais padrões de consumo e seus pressupostos éticos. Torna-se necessário associar o reconhecimento das limitações físicas da Terra ao reconhecimento do princípio universal de equidade na distribuição e acesso aos recursos indispensáveis à vida humana (CORTEZ; ORTIGOZA, 2009, p. 51).

Problemas sociais e ambientais se apresentam evidenciando o colapso e a ineficiência do sistema até agora estabelecido, mas também expondo novos valores que agora contrapõem os aspectos que até então caracterizavam o sentido de bem-estar coletivo, uma vez que, pelo que foi exposto, este não consegue produzir mais resultados que acalentem as necessidades básicas de uma população (CAVALCANTI; ARRUDA; NONATO, 2017; MANZINI, 2008). 


\section{Design, responsabilidade e ética profissional}

As profissões e áreas do conhecimento tendem a refletir em busca de soluções mais sustentáveis. Nesse contexto, uma saída para a mudança do sistema de consumo visando a um sistema sustentável pode estar atrelada não aos produtos, mas sim aos projetos, sendo possível planejar e contextualizar os bens e serviços ao ambiente e à cultura onde eles serão utilizados (CAVALCANTI; ARRUDA; NONATO, 2017; MANZINI, 2008). Embora atue diretamente com os hábitos do consumidor, o design vem assumindo um caminho cômodo de acompanhar os valores contemporâneos que baseiam seu bem-estar social por meio do consumo. Por causa da qualidade contemporânea da profissão, os limites pouco sólidos, a característica multidisciplinar e a falta de reflexão podem ser desfavoráveis em justamente conceber ou demonstrar engajamento no sentido de orientar a profissão a quebrar seus paradigmas. Assim, Cardoso (2012, p. 18) comenta: “Todo mito fundador possui um fundo de verdade e, portanto, faz-se necessário substituir os paradigmas antigos por novos, senão corre-se o risco de perder toda e qualquer visão de futuro".

Designers são responsáveis por projetos produzidos e comercializados. No entanto, seu papel vem se alterando durante os anos, não limitado se limitando a atender a indústria de consumo, focada somente na competitividade dos produtos e concorrência das empresas, mas acompanhando as evoluções sociais. $O$ design ampliou sua atuação e está cada vez mais próximo do cotidiano das pessoas e influencia tanto sistemas supérfluos quanto sistemas vitais da sociedade, e, assim podemos rastrear a atuação do design acompanhado sempre de inovações tecnológicas (CAVALCANTI; ARRUDA; NONATO, 2017; MANZINI, 2008). Contudo, acompanhar o modus operandi do mercado não traz inovação social substancial para a mudança do sistema socioeconômico, pois contribui com produtos e sistemas que compactuam com a produção em massa. Para a sustentabilidade do sistema e consequentemente a preservação do meio ambiente, requer-se uma mudança de postura ética, pertinente às suas condutas profissionais e atitudes humanas (MONTEIRO, 2019; MORAES; KRUCKEN, 2009).

Flusser e Cardoso (2017) admoestam que a evolução se deu de tal forma que houve uma inversão, passando os homens a servirem às máquinas, e não o inverso, como era de se esperar. Assim, antes, na produção de uma fábrica, máquinas e ferramentas eram substituídas quando davam defeitos, mas, com a evolução tecnológica, aumentou a durabilidade e a eficiência desses dispositivos, e assim tornou-se o homem frequentemente o componente mais substituível na linha de produção. Logo, os avanços tecnológicos abriram um horizonte de oportunidades para implementar mudanças técnicas, mas estes requerem uma profunda reflexão a respeito das consequências dos projetos elaborados. Faz-se necessário que haja consciência sobre os valores que deseja fortalecer, de preferência ao encontro da distribuição das benesses para todos os cidadãos, para que haja de fato a mudança de paradigma. 
Flusser e Cardoso (2017) continuam a dizer que, com a sociedade pós-industrial e a automação, o mundo terá como consequência a construção de máquinas inorgânicas inteligentes, que fundirá a durabilidade do material com a inteligência do orgânico, servindo o designer como projetista dessa nova realidade. Todavia, essa interação não apresenta apenas benefícios para a humanidade, uma vez que, no entendimento do autor, à medida que as máquinas se tornam mais artificialmente inteligentes, novos fenômenos até então imprevisíveis podem acontecer.

\begin{abstract}
Atualmente este contra-ataque das máquinas está se tornando mais evidente: os jovens dançam como robôs, os políticos tomam decisões de acordo com cenários computadorizados, os cientistas pensam digitalmente e os artistas desenham com máquinas de plotagem (FLUSSER; CARDOSO, 2017, p. 45-46).
\end{abstract}

Desse modo, e por muito tempo, a inovação vem sendo percebida e implementada sob o prisma dos avanços tecnológicos na indústria de consumo. Contudo, vislumbram-se mudanças ligadas à sociedade, pois há ações coletivas que buscam o bem-estar comum para servir de modelo para mudanças tecnológicas. Tal contexto estabelece uma visão para além de vendas e margem de lucros, pois o "Design para o bem-estar [...] deve buscar não só influenciar ações e decisões humanas em desejáveis direções, mas também possibilitar que os usuários desenvolvam relação ativa e crítica com essas influências" (DORRESTIJN; VERBEEK, 2013, p. 54).

Manzini (2008) já afirmava que as inovações sociais hoje são até mais importantes do que as inovações tecnológicas, mas deixa claro que um sistema sustentável deve estar apoiado nas inovações tecnológicas. Esse percurso só é exequível em via de mão dupla, em outras palavras, é importante haver tanto a humanização das tecnologias como o inverso, ou seja, uma "tecnologização" das sociedades para sua total operacionalidade (ARRUDA, 2017; MANZINI, 2008).

\footnotetext{
Em contraste, o design social e as intervenções de diretivas conduzem implicitamente o comportamento numa direção desejável (por exemplo, colocando alimentos saudáveis ao nível dos olhos em refeitórios escolares para promover uma alimentação saudável), enquanto ainda permite aos usuários a liberdade de fazer uma escolha diferente (por exemplo, escolhendo alimentos não saudáveis em vez de alimentos saudáveis). Projetar considerando dilemas equilibra a transparência das tecnologias persuasivas, com a intenção de apoiar a formação de um "sistema de auto-ajuda" ao lidar com esses dilemas (OZKARAMANLI; DESMET; OZCAN, 2016, p. 89, tradução nossa).
} 
Dessa forma, a fabricação de toda e qualquer máquina ou produto deve considerar, em sua projetação, os impactos que tal tecnologia apresentará, não se restringindo apenas aos fatores econômicos e ecológicos como norteadores da sua construção. Essa colocação já era prevista por Papanek (1995), quando disse que os designers são responsáveis pelas coisas que colocam no mundo e sua responsabilidade pelos efeitos que estas têm sobre esse mundo. Logo, é impossível se eximir de qualquer obrigação ética com aquilo que é criado e produzido.

Consoante a isso, Manzini (2008) complementa que o design é a profissão mais ligada ao cotidiano dos cidadãos e, por isso, o designer deve ter ainda mais responsabilidade na elaboração de seus projetos. Ainda convém lembrar que o resultado do trabalho do designer é amplo e tem influência em toda a sociedade, e não somente nas partes diretamente envolvidas. $O$ que vai ser feito, como será feito, como será usado, reutilizado, descartado, essas variáveis implicam toda a coletividade, e não somente o público-alvo consumidor. Para Devon e De Poel (2004, p. 467, tradução nossa), "o design implica não só uma transformação do mundo físico, mas também de uma sociedade. Projetar impactos em outras pessoas que não as envolvidas na sua construção".

Retomando Flusser e Cardoso (2017), é neste momento de dominação tecnológica que mais se faz imprescindível o trabalho do designer, pois ele deve projetar as máquinas para que seu contragolpe não traga dor para a humanidade. Talvez por isso, sugere Monteiro (2019), deve-se compreender a importância do papel do designer na sociedade, entender o quão importante ele é, e entender que para o pleno funcionamento desse sistema em vigor a participação desse profissional é vital. Monteiro (2019) ainda explicita que a falta de ética do designer está evidente na inteira falta de reflexão a respeito de sua ocupação. Isso confere a ele uma total aderência com este sistema socioeconômico mundial, pois o designer está disposto a aceitar toda e qualquer demanda que possa ser atendida pelo conhecimento de seu ofício. Pode-se verificar isso quando o profissional participa sem questionamento da produção de artefatos, serviços e ferramentas digitais que contribuem para poluição, assédio, disseminação de ódio, padronização social, obsolescência planejada, desconfiguração social e bullying. Aspectos evidentes da nossa falta de organização profissional que aceita contribuir para a promoção do sistema exatamente como é, como se não fizéssemos parte e não fôssemos prejudicados.

Por isso, a função do design contemporâneo inclui refletir a respeito do fato que toda criação tem uma intencionalidade, seja esta percebida ou não. $O$ designer projeta não somente para resolver problemas, uma vez que deve ter uma intenção para seus projetos e, acima de tudo, também deve repensar a respeito de suas intenções; como coloca Sartre (1970, p. 14), “A escolha é possível, em certo sentido, porém o que não é possível é não escolher. Eu posso sempre escolher, mas devo estar ciente de que, se não escolher, assim mesmo estarei escolhendo". Portanto, cabe aos designers desenvolverem um senso crítico em relação a suas propostas e prever o efeito que estas têm sobre os indivíduos e a sociedade como um todo (MANZINI, 2008; OZKARAMANLI; DESMET; OZCAN, 2016). 
O questionamento que surge posteriormente é sobre até que ponto a interferência no comportamento das pessoas é algo ético e aceitável. As expressões colocadas por Manzini (2008, p. 23), como "princípios de justiça", "responsabilidade em relação ao futuro" e "espaço ambiental", dizem respeito à maneira como seres humanos utilizam os recursos e espaços ao seu redor, mantendo um ciclo mínimo de reposição e recuperação para que, no futuro, a vida seja conservada. Nesse sentido, fica clara a relevância de áreas responsáveis por projetar ou modificar identidades e comportamentos, como o consumo aqui abordado, que em grande parte interfere no construto social.

Nesse sentido, o papel do designer é atuar de maneira responsável, ética e abrangente, exercendo a responsabilidade social de modo pleno, não somente na entrega do produto final. Conforme Denis (1998 p. 16), "ao perguntarmos se a natureza do design se pauta em seus produtos ou em seus processos, a única resposta remotamente plausível parece ser: em ambos". Portanto, o profissional tem que zelar pelo bem-estar social, desde a ideia inicial de um projeto, aplicando os princípios de um design responsável e sustentável, incluindo a idealização do projeto inicial até a comercialização responsável do produto final. $\mathrm{E}$ ir além, planejar previamente o descarte consciente, reúso ou reciclagem do produto depois da utilização pelo consumidor.

\section{Bem-estar não é estar bem}

O status quo humano transita entre a aceitação de uma vida mediana e a busca pelo bem-estar. Devido a isso, as emoções exercem um papel fundamental, pois impulsionam cada pessoa para ações e resultados antes não alcançados, decorrendo daí avanços tecnológicos ou sociais. Na medida em que a vida em sociedade é característica do homem, emoções positivas também são geradas ao proporcionar a outras pessoas melhores condições, seja por meio de produtos, serviços, seja por meio de interações sociais positivas (DAMÁSIO, 2018).

Por outro lado, Bauman $(2001,2008)$ defende um novo conceito que é característico da contemporaneidade: a liquidez. 0 autor defende o termo "modernidade líquida" em contraposição ao conceito de pós-modernidade. Segundo ele, a sociedade globalizada alimenta princípios como o individualismo e o consumismo, resultando na efemeridade das relações sociais. Esse cenário contribui com o desmantelamento de estruturas sólidas clássicas, aspecto principal que caracteriza a modernidade. Nesse panorama, já podemos perceber que o bem-estar, tal qual conhecemos, não reflete a ideia de ser algo positivo para as pessoas que vivem em sociedade.

O próprio consumismo se traveste em instrumentos que operacionalizam uma falsa sensação de individualidade e controle sobre a produção. As palavras de ordem da atualidade são "customização" (adequação do produto ao consumidor) e "qualidade total do processo de fabricação", que 
inclui responsabilidades sociais e ambientais em sua confecção, apesar de nem sempre respeitados na prática. Para Cardoso (2012, p. 107), "A maioria das pessoas rejeita a noção de que todos teriam que se vestir de modo igual ou dirigir o mesmo carro". o projetista hoje em dia tem mais ferramentas à disposição para que possa corresponder à expectativa do consumidor, até mesmo de forma individualizada, resultando em mais prazer ao consumir produtos e serviços.

Tal pensamento afasta-se cada vez mais da fabricação industrial para consumo em massa e produção em série, sobre a qual uma vez respondeu Henry Ford3 a respeito das cores que os consumidores poderiam comprar seus veículos: "Qualquer cor, contanto que seja preto". Não obstante, o novo paradigma centrado na customização, com a evolução das máquinas, tecnologias e novas técnicas de produção e montagem, como as impressoras 3D, por exemplo, permitem que os produtos sejam mais próximos do gosto individual de cada consumidor. Todavia, é notório que tal possiblidade abre caminho para o aumento do consumo e da obsolescência, porquanto se torna mais fácil a substituição de um bem por outro de maneira mais célere e eficaz. $O$ produto que antes era produzido para durar agora pode ser descartável, pois a facilidade de aquisição aumenta na mesma proporção que o consumidor altera os seus gostos e experimenta novas tendências (SCHWAB; DAVIS, 2018).

Sob o holofote do sistema econômico, o capitalismo inclui a busca do lucro dentro de um sistema pretensamente livre, ou seja, o consumidor pode comprar o que desejar. E, segundo essa lógica, os fornecedores se empenham em disponibilizar o que tem mais vendagem e o que os consumidores estejam dispostos a pagar. A partir do séc. XX, o campo do design aponta para o caminho da desmaterialização, ou seja, formas diferentes de enxergar os recursos existentes e as relações humanas, com novas formas de pensar e articular projetos, evidente quando surgem termos como design de serviços, design social e design sistêmico.

A inovação social, conceito abordado por André e Abreu (2006), Arruda (2017) e Manzini (2008), consiste em um vetor para a mudança que propõe solucionar questões humanas que o sistema de mercado não contempla e viabilizar a inclusão social, modificar padrões sociais preestabelecidos e normas culturais. Manzini propõe um bem-estar ativo, indo de encontro ao modelo de bem-estar contemplativo que a sociedade de consumo moderna estabeleceu. A ideia é que cada indivíduo desenvolva capacidades de cuidar de si mesmo e daqueles que estão a sua volta. Essa proposta retoma padrões de desenvolvimento anteriores às Revoluções Industriais e contrapõe a situação estabelecida atualmente, na qual Bauman (2001) aponta que o individualismo rege o cotidiano das sociedades contemporâneas, nas quais a busca pela felicidade e satisfação "pessoal", como o próprio termo demonstra, é o mais importante. 


\section{Considerações finais}

A ética profissional deve ser um ponto primordial na discussão de qualquer projeto que venha a ser executado pelo designer, pois a ideia de propor mudanças, neste caso abordando o alcance de um verdadeiro bem-estar social, terá impacto direto sobre as estruturas socioeconômicas. Lidar com dilemas como crescimento econômico e manutenção sustentável deve, sobretudo, estar atrelado ao despertar consciente dos designers como programadores de sistemas sustentáveis e não se comportar conforme o programa atual, como programas concebidos para manter esse sistema baseado no consumo insustentável de recursos naturais.

A mudança de sistema passa também pela mudança de postura daqueles que o promovem e o sustentam. Designers devem pensar não como as minorias, mas devem trazer as minorias para o projeto, pois a participação da construção de um sistema pensado por parcelas da sociedade e ramos empresariais tendem a atender às necessidades desse grupo em específico. Designers podem ser contratados por empresas ou empresários, mas não devem servir única e exclusivamente a seus propósitos, e sim à sociedade para a qual o produto ou serviço será fornecido.

Desse modo, a percepção de bem-estar por meio do consumo foi construída na beleza dos produtos e serviços produzidos, e não pela intenção de proporcionar um sistema confortável para a sociedade. A intenção de manter um sistema socioeconômico insustentável e prejudicial aos cidadãos demonstra um comportamento antiético dos profissionais que contribuíram para sua manutenção. 0 designer, porém, tem atualmente a maturidade de aproveitar a oportunidade dos avanços tecnológicos, e assim se organizar profissionalmente e seguir uma conduta ética profissional que viabilize, daqui em diante, a incorporação de intenções para melhorar o bem-estar humano e a sustentabilidade do meio ambiente em seus projetos.

1 A primeira Revolução Industrial envolve o período de 1760 a 1820/40, quando ocorre a transição dos métodos de produção artesanais para a produção industrial, com a utilização de máquinas e uso crescente da energia a vapor.

2 Neologismo que surge a partir do nome da rede social Instagram, o sentido aqui é que todas as ações das pessoas devem gerar algum conteúdo, ou seja, belas fotos ou vídeos.

3 Henry Ford (1863-1947) foi um empreendedor estadunidense, fundador da Ford Motor Company, e o primeiro a aplicar a linha de montagem em série para produzir automóveis em menos tempo e com menor custo. 


\section{Referências}

ANDRÉ, I.; ABREU, A. Dimensões e espaços da inovação social. Finisterra, v. 41, n. 81, p. 121141, 2006

ARRUDA, A. J. V. Design e inovação social. São Paulo: Blucher, 2017.

BAUMAN, Z. Modernidade líquida. Tradução: Plínio Dentzien. Rio de Janeiro: Zahar, 2001. BAUMAN, Z. Vida para consumo. Tradução: Carlos Alberto Medeiros. Rio de Janeiro: Zahar, 2008.

CARDOSO, R. Design para um mundo complexo. São Paulo: Cosac Naify, 2012.

CAVALCANTI, A. V.; ARRUDA, A. O.; NONATO, C. B. Sustentabilidade no século XXI: história e possibilidades de avanços através do PSS. In: CAVALCANTI, A. V.; ARRUDA, A. O.; NONATO, C. B. (org.). Design e complexidade. São Paulo: Editora Blucher, 2017, p. 43-60.

CORTEZ, A. T. C.; ORTIGOZA, S. A. G. (org.). Da produção ao consumo: impactos socioambientais no espaço urbano [online]. São Paulo: Editora UNESP; São Paulo: Cultura Acadêmica, 2009. DAMÁSIO, A. A estranha ordem das coisas: as origens biológicas dos sentimentos e da cultura. Tradução: Laura Teixeira Motta. São Paulo: Companhia das Letras, 2018. E-book.

DENIS, R. C. Design, cultura material e o fetichismo dos objetos. Arcos, v. 1, n. único, p. 1539, 1998.

DEVON, R.; VAN DE POEL, I. Design ethics: the social ethics paradigm. Int. J. Engn. Ed., v. 20, n. 3, p. 461-469, 2004.

DORRESTIJN, S.; VERBEEK, P. P. Technology, wellbeing, and freedom: The legacy of utopian design. International Journal of Design, v. 7, n. 3, 2013.

FLUSSER, V.; CARDOSO, R. (org.). o mundo codificado: por uma filosofia do design e da comunicação. Tradução: Raquel Abi-Sâmara. São Paulo: Ubu, 2017.

JAMESON, F. A cidade do futuro. Libertas, v. 10, n. 1, p. 181-200, jan. 2010.

LIPOVETSKY, G.; SERROY, J. A estetização do mundo: viver na era do capitalismo artista. Tradução: Eduardo Brandão. São Paulo: Companhia das Letras, 2014. E-book.

LLOSA, M. V. A civilização do espetáculo: uma radiografia do nosso tempo e da nossa cultura. Tradução: Ivone Benedetti. Rio de Janeiro: Objetiva, 2013.

MANZINI, E. Design para a inovação social e sustentabilidade: comunidades criativas, organizações colaborativas e novas redes projetuais. Tradução: Carla Cipolla. Rio de Janeiro: E-papers, 2008. v. 1.

MONTEIRO, M. Ruined by design: how designers destroyed the world and what we can do to fix it. San Francisco, CA: Mule Design, 2019. E-book.

MORAES, D. de; KRUCKEN, L. Cadernos de estudos avançados em Design: design e sustentabilidade I. Barbacena: EdUEMG, 2009.

OZKARAMANLI, D.; DESMET, P. M. A.; OZCAN, E. Beyond resolving dilemmas: three design directions for addressing intrapersonal concern conflicts. Design Issues, v. 32, n. 3, p. 78-91, 2016. PAPANEK, V. Arquitectura e design. Ecologia e ética. Lisboa: Edições70, 1995.

PINTO, J. Os gurus e o consumo: notas sobre a recepção dos bens esotéricos. Geraes Revista de Comunicação Social, n. 48, p. 19-22, 1997.

SARTRE, J.-P. Existencialismo é um humanismo. Rio de Janeiro: Vozes, 1970. SCHWAB, K.; DAVIS, N. Shaping the fourth industrial revolution. Geneva: World Economic Forum, 2018. E-book.

Recebido: 04 de agosto de 2020 . Aprovado: 24 de agosto de 2020 . 